\title{
Knowledge on breast cancer and Practices on breast self-examination among Female Students in Faculty of Health-Care Sciences, Eastern University, Sri Lanka
}

\author{
Karthijekan $\mathrm{K}^{1}$ and Karunakaran $\mathrm{KE}^{2}$ \\ ${ }^{1}$ Department of Supplementary Health Sciences, Faculty of Health-Care Sciences, Eastern University, Sri \\ Lanka \\ ${ }^{2}$ Department of Clinical Sciences, Faculty of Health-Care Sciences, Eastern University, Sri Lanka
}

\begin{abstract}
Breast cancer is the most common cancer diagnosed among women. Overall, it is the fifth leading cause of cancer deaths in the world. However, it is being highest mortality among all cancer death in women. Global incidence of breast cancer has been rising over the last few decades. Knowledge about breast cancer is very important in the prevention of the disease. The objective of this study was to assess the level of knowledge and examine the practice of female students about self-breast examination in Faculty of Health-Care Sciences, Eastern University, Sri Lanka. A cross sectional descriptive study involving 222 female students aged 20-30 years was carried out using a17 item structured self-administered questionnaire between March and September 2016. Among total participants, $23.4 \%$ were nursing and $76.6 \%$ were medical students. Ethnically, $55.9 \%$ were Sinhalese, 20.2\% were Tamils and 23.9\% were Muslims. Majority of the participants (96.8\%) heard about breast cancer. Source of information such as Newspapers/Magazines (78.8\%) lectures (60.8\%) and internet (66.2\%) were respectively. Most of them (82.9\%) heard about breast self-examination (BSE) but only 33\% have ever done it; of those, 9.6\% did it because one of their family members had breast cancer. Awareness about risk factors such as positive family history (82.9\%), use of oral contraceptive pills (58.6\%), no breast feeding (68.0\%), and early menarche (45.9\%) were respectively. Breast lump, recent onset nipple discharge, pain on breast and skin changes of breast were stated as clinical features by 95.9\%, 84.2\%, 71.2\% and 79.3\% participants, respectively. Knowledge of treatments methods such as surgery (96.8\%), radiotherapy (88.3\%), chemotherapy (82\%), and hormone pills (24.8\%) were respectively. The knowledge regarding breast cancer was good but less than half of the students had performed breast self-examination in their life.
\end{abstract}

KEYWORDS: Knowledge, Self-examination, Breast Cancer, Female students 


\section{INTRODUCTION}

Breast cancer is the most frequent cancer among women, impacting 1.5 million women in each year. The greatest number of cancer-related deaths among women results from breast cancer. According to the latest data published by world Health Organization in 2017, 570,000 deaths occurred from breast cancer among women. It accounted approximately $15 \%$ of the all cancer deaths among women (WHO, 2017). Global incidence of breast cancer has been rising over the last few decades with more and more; younger females being the victims. The incidence of breast cancer is increasing in the developing world due to increased life expectancy, increased urbanization and adoption of western lifestyle (WHO, 2014). Even in Sri Lanka the cancer incidences now steadily are increasing. Unlike the world statistics, the highest cancer incidence rate among women in Sri Lanka is the breast cancer (Ministry of Health, 2012). Hospitalization due to neoplasm has been continuously increased from 2009 in Sri Lanka. The neoplasm is the second leading causes of hospital deaths since 2010 in Sri Lanka and breast cancer is the commonest cancer accounting for $18.8 \%$ of newly diagnosed female cancers in 2012 (WHO, 2014).

According to the latest WHO data published in May 2014 breast cancer death in Sri Lanka reached 1,361 or $1.07 \%$ of total deaths. The age adjusted death rate is 11.6 per 100.000 of population (WHO, 2014). A considerable proportion of cancer cases report to healthcare institution for diagnosis and treatment in advanced stages of the disease, resulting in poor survival and high mortality rates. Cancer is still associated with a lot of fear and to a lesser extent stigma in the country (Ministry of Health, Nutrition and Indigenous medicine, 2015).

Breast cancer causes are unknown, but there are some risk factors associated with breast cancer such as simply being a female, getting older, family history of breast cancer especially a firstdegree relative, early menarche at the age of 12 and under, late menopause after the age of 55 years, having the first child after the age of 30 years, null parity, prolonged use of oral contraceptive pills, hormonal therapy, and being overweight or obese (Taba'r, Duffy \& Vitak et $a l$, 1999). The symptoms of breast cancer includes lump in the breast, nipple discharge and itching. There are many techniques to treat breast cancer. Surgery plays a vital role, supported by chemotherapy, radiotherapy and hormonal therapy (Naomal, 2015). Since breast cancer is a progressive disease, small tumours are more likely to be at an early stage and their early detection is more likely to have successful treatment and a better prognosis (Sherma \& Hossfeld, 1990).

Early detection of breast cancer plays an important role in improving breast cancer outcome and survival. There is no evidence on the effect of screening through breast selfexamination (BSE.) However, the practice of BSE has been seen to empower women, taking responsibility for their own health. Therefore, BSE recommended for raising awareness among women at risk rather than a screening method (WHO, 2014). BSE involves feeling the breast for limps or other abnormalities. Verma, in 2013, claimed that women who correctly practice BSE monthly are more likely to detect a lump in the early stage, with early diagnosis and treatment yielding better survival (Verma, 2013). The poor knowledge and wrong beliefs about breast cancer prevention among women are responsible for a negative perception of the curability of a cancer detected early and of the efficacy of the screening tests (Haris, Lippman \&Veronesi, 1992).

A study done among adolescent female students in Colombo found that there were significant deficiencies in knowledge, attitudes and practices on breast cancer among study population (Ranasinghe et al, 2013). It should be assessed to make recommendations about improving the knowledge and the existing practice on self-breast examination. More ever, educating the youth on breast cancer is a 
potential strategy for dissemination of such information in society. Therefore, this study was designed to evaluate the knowledge of breast cancer and self-breast examination practice among female students of Faculty of Health-Care Sciences, Eastern University, Sri Lanka to make recommendations about improving the knowledge and the early detection of breast cancer.

\section{METHODOLOGY}

\section{A. Study Population}

This was a descriptive cross sectional study carried out since March to September 2016 to assess the knowledge of Breast cancer and practice of self-breast examination among 222 female students in Faculty of Health-Care sciences, Eastern University, Sri Lanka. The ethical clearance was obtained from the ethical review committee Faculty of Health-Care sciences, Eastern University, Sri Lanka.

\section{B. Data Collection and Data Instruments}

Data were collected from those willing to participate in the study; respondents who were not present at the time of study, who refused to participate in the study, were excluded from the study. The respondents were informed about the study and inform consent was obtained before the data collection. Anonymity was ensured throughout the study. Data were collected by investigators through a self-administered questionnaire. The pre-test was carried out among 15 students to check the understanding and accuracy of the questionnaire. The study instrument initially was developed in English. Then it translated in to Tamil and Sinhala. The questionnaire was distributed to the students in their own language as Tamil and Sinhala. The original questionaries contained 17 questions including socio-demographic details of participants, knowledge questions about breast cancer including risk factors, warning signs and treatment options and practice of self-breast examination among female students. The knowledge questions were answered using "Yes",

"No" and "Do not know".

\section{Statistical Analysis}

Collected data were transferred to Statistical package for social sciences (SPSS) version 18 and analysed based on the research problem, objectives and variables. Descriptive statistical results were present as percentage.

\section{RESULTS}

\section{A. Description of the socio-demographic details of study samples}

The study was conducted among 222 female students in Faculty of Health-Care sciences, Eastern University, Sri Lanka. Among 222 participants, $23.4 \%$ studied nursing and $76.6 \%$ studied medicine. Ethnically, 55.9\% were Sinhalese, $20.2 \%$ were Tamils and $23.9 \%$ were Muslims. Most of the participants were residents at hostel (65.8\%). Majority of the students (96.8\%) had heard about breast cancer. Source of information such as Newspapers/Magazines (78.8\%) lectures (60.8\%) and internet (66.2\%) were respectively. Socio-demographic details are mentioned in Table 1.

\section{B. Description of knowledge of Breast Cancer among participants}

\section{i. Knowledge of Risk factors}

Knowledge about risk factors of breast cancer among female students is shown in table 2. This part of the questionnaire consists of 6 important risk factors and responses were recorder as yes or no or don't know. Majority of the students identified (82.9\%) family history as a risk factors for breast cancer, followed by not breast feeding (68.0\%), oral contraceptive use (58.6\%) and late menopause (50.9\%). But less than half of the participants identified early menarche (45.9\%) and high fat diet (40.5\%) as risk factors for breast cancer. 
Table 1. Description of socio-demographic details of study sample

\begin{tabular}{|l|r|r|}
\hline Variables (n=222) & Number & $\begin{array}{l}\text { Percentage } \\
\text { (100\%) }\end{array}$ \\
\hline Discipline & & \\
Nursing & 52 & 23.4 \\
Medicine & 170 & 76.6 \\
Age & 10 & \\
Less than 21 & 150 & 4.5 \\
21-24 & 62 & 27.6 \\
More than 24 & & \\
Ethnicity & 45 & 20.2 \\
Tamil & 124 & 55.9 \\
Sinhala & 53 & 23.9 \\
Muslim & & \\
Academic year & 45 & 20.4 \\
First Year & 55 & 24.9 \\
Second Year & 40 & 18.1 \\
Third Year & 64 & 29.0 \\
Fourth Year & 17 & 7.7 \\
Fifth Year & & \\
Residence & 31 & 14.0 \\
Home & 146 & 65.8 \\
Hostel & 45 & 20.3 \\
Others & & \\
Source of information & 175 & 78.8 \\
Newspaper/Magazine & 130 & 58.6 \\
Health officers & 147 & 66.2 \\
Internet & 126 & 56.8 \\
Friends/Relatives & 135 & 60.8 \\
Lectures/Seminars & 149 & 67.1 \\
Television & & \\
Breast Cancer & & \\
Awareness & & \\
Yes & & \\
No & & \\
& & \\
\hline
\end{tabular}

\section{ii. Knowledge of Warning signs}

Knowledge about warnings signs of breast cancer among female students is shown in table 2. The participants were asked about the 7 important warnings signs for breast cancer and their responses were recorder as yes or no or don't know. Majority $\left(3 / 4^{\text {th }}\right)$ of the students were aware about the presenting symptoms of breast cancer. Among 222 participants, a total of 95.9\%, 84.2\% and $71.2 \%$ correctly identified Breast lump, recent onset nipple discharge and pain in breast as the most common symptoms of breast cancer. The younger women should be aware about the symptoms of breast cancer for the early treatment as much as possible and it will help to reduce the complication of breast cancer and promote their health.

Table 2. Describe the knowledge of breast cancer among participants

\begin{tabular}{|c|c|c|c|}
\hline Variables $(n=222)$ & $\begin{array}{l}\text { Yes } \\
(\%)\end{array}$ & $\begin{array}{r}\text { No } \\
(\%)\end{array}$ & $\begin{array}{l}\text { Don't } \\
\text { know } \\
(\%)\end{array}$ \\
\hline \multicolumn{4}{|l|}{ Risk Factors } \\
\hline Family history & 82.9 & 7.7 & 9.5 \\
\hline Oral contraceptive use & 58.6 & 22.5 & 18.9 \\
\hline No breast feeding & 68.0 & 18.9 & 13.1 \\
\hline Early menarche & 45.9 & 26.1 & 27.9 \\
\hline Late menopause & 50.9 & 21.6 & 27.5 \\
\hline High fat diet & 40.5 & 31.1 & 28.4 \\
\hline \multicolumn{4}{|l|}{ Warning Signs } \\
\hline Breast Lump & 95.9 & 1.8 & 2.3 \\
\hline $\begin{array}{l}\text { Recent onset nipple } \\
\text { discharge }\end{array}$ & 84.2 & 2.7 & 13.1 \\
\hline $\begin{array}{l}\text { Recent onset nipple } \\
\text { retraction }\end{array}$ & 71.2 & 6.3 & 22.5 \\
\hline Pain on breast & 71.2 & 18.0 & 10.8 \\
\hline Asymmetry of the & 73.0 & 10.4 & 16.7 \\
\hline breast & 71.2 & 9.5 & 19.4 \\
\hline $\begin{array}{l}\text { Lump in neck or } \\
\text { armpit }\end{array}$ & 79.3 & 5.4 & 15.3 \\
\hline Skin changes of breast & 96.8 & 0.9 & 2.3 \\
\hline Treatment methods & 88.3 & 3.2 & 8.6 \\
\hline Surgery & 82.0 & 5.0 & 13.1 \\
\hline $\begin{array}{l}\text { Radiotherapy } \\
\text { Chemotherapy } \\
\text { Hormone pills }\end{array}$ & 24.8 & 28.8 & 46.4 \\
\hline
\end{tabular}

\section{iii. Knowledge of Treatment option}

Knowledge about treatment option for breast cancer among female students is shown in table 2. This part inquired about 4 important treatment options for breast cancer. In this study majority (more than 80\%) of the participants were aware about the treatment options such as surgery (96.8\%), radiotherapy (88.3\%) and 
chemotherapy (82.0\%). However nearly one fourth $(24.8 \%)$ of the participants claimed that hormone pills is a treatment option for breast cancer. The female adolescents must be aware about the available treatments option for breast cancer to get optimum care which will help to improve the health.

\section{Knowledge and practice of breast self-examination}

Breast self-examination is useful for females to find out the earlier changes in their breast which are favourable to develop as breast cancer in future. By properly doing this, they may be able to identify the changes in the breast. Fig 1 describes the awareness of breast selfexamination.Among all participants, majority of them (82.9\%) were aware about breast selfexamination (Figure1). Of those who were aware only $32.9 \%$ had practiced breast examination at least once in their life for various reasons. (Figure2). The reasons for doing this as follows, advice from health officers (19.2\%), special medical checkup (4.1\%), presence of lump in breast (4.1\%) and one of family members had breast cancer (9.6\%) (Table 3).

In our study nearly two third of the students had not performed BSE. The reasons for not performing BSE lack of knowledge about technique of BSE (23.5\%), lack of interest (25.3\%) and fear about the results (8.1) were respectively (Table 4).

\section{Practice of breast-self examination}

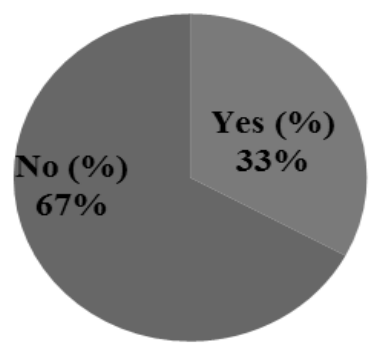

Figure 1. Awareness of breast self-examination

\section{Awareness of Breast Self-Examination}

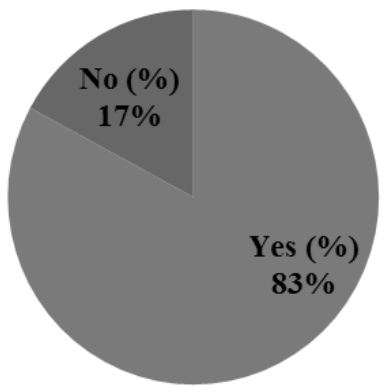

Figure 2. Practice of breast self-examination among participants

Table 3. Description of reasons for doing breast self-examination

\begin{tabular}{|l|r|}
\hline Variables (n=73) & $\begin{array}{r}\text { Yes } \\
\text { (\%) }\end{array}$ \\
\hline & \\
Reason for doing BSE & 19.2 \\
Advice from health officers & 4.1 \\
Special medical check up & 4.1 \\
Presence of Lump in breast & 9.6 \\
Family member had breast cancer & \\
\hline
\end{tabular}

Table 4. Description of reasons for not doing breast self- examination

\begin{tabular}{|l|r|}
\hline Variables (n=149) & $\begin{array}{r}\text { Yes } \\
\text { (\%) }\end{array}$ \\
\hline $\begin{array}{l}\text { Reason for not doing BSE } \\
\text { I don't know about it }\end{array}$ \\
$\begin{array}{l}\text { Lack of knowledge about technique of } \\
\text { BSE }\end{array}$ \\
$\begin{array}{l}\text { I'm afraid of knowing the result I'm not } \\
\text { interested }\end{array}$ \\
& 3.1 \\
\hline
\end{tabular}

\section{DISCUSSION}

Breast cancer is the commonest cancer among women in this world. It is also the biggest cancer killer among women. According to WHO 
estimates approximately 4000 Sri Lankan women are diagnose with breast cancer and almost a third of this number succumb to breast cancer each year. The rate of breast cancer in developing countries including Sri Lanka is still rising steadily (Ferley et al., 2013). It is already a major public health problem in Sri Lanka and is likely to get worse in the future. While improving and upgrading the diagnostic and treatment facilities for breast cancer, the proper educational programs would carry out to minimize the consequences from breast cancer (Seneviratne, 2016). Breast cancer is also the most common causes of cancer death among women and the most frequently diagnosed cancer among women in 140 of 184 countries worldwide (WHO, 2013).

The educational programme is effective in improving the knowledge on breast cancer, perception regarding breast cancer, attitudes towards breast cancer and BSE. It is recommended that health education programs for university students, and the curriculum of the university should include some health related issues (Moostafa et al., 2015). To our knowledge there are no published data on knowledge and practices among university female students on breast cancer in Sri Lanka, and few studies published in worldwide. However, a study published in Sri Lanka among adolescent females' students in Colombo district and this study were assessed knowledge, attitudes and practices regarding breast cancer (Ranasinghe $e t$ al, 2013).

The present study assessed female student's knowledge of breast cancer and practices on BSE. This study showed that majority of the students had good knowledge regarding breast cancer. The same findings observed in a study conducted in Nigeria in 2008 (Osime, 2008). A study done Ethiopia in 2014 (Segni et al, 2014), Pakistan 2010 (Khokher, 2011) and Saudi Arabia in 2013 (Nemenqani, 2014) claimed that the majority of the respondents had low knowledge.
The present study revealed that knowledge regrading risk factors for breast cancer in this sample was average. The majority of students were answered that positive family history as a risk factor. However, they did not well aware about other risk factors for breast cancer. A study conducted in Oman among female university students found that students had very good knowledge about the risk factors except early menarche. The most widely known risk factor was family history (86.62 \%) and least one was early menarche (49\%). Knowledge of risk factors is very important role in the reduction of breast cancer incident rate and reduces the morbidity and mortality among world population (Al-Junaibi \& Alam Khan, 2011). Ranasinghe et al, in 2013, found that the knowledge was poor among adolescent students regarding risk factors for breast cancer. Study by Suleiman, in 2012, reported that half of the respondents were aware of breast cancer. Among these, less than one quarter of the respondents believed that it was caused by a medical condition, followed by old age (16.4\%), lack of breast feeding (13.3\%) and heredity (12.8\%) (Suleiman, 2014).

This study claimed that majority of the students were aware about the warning signs for breast cancer. They had significantly better knowledge in warning signs of breast cancer. A study done among female university students in Saudi Arabia in 2012, found that more than half of the students (65.3\%) knew recent onset nipple discharge as an important warning sign followed by pain in breast (58.7\%), presence of breast lump (55.3\%) and ulceration (53.3\%) (Latif, 2014). This study showed that most participants had better knowledge about treatment option except hormone pills which identified as a treatment option nearly one fourth of the students. Study by Ranasinghe et al, in 2013, found that one third of the sample mentioned that they are unaware of treatments. Of those who were aware, $90.6 \%$ named surgery as a treatment option for breast cancer, $79.4 \%$ were unaware that chemotherapy is used. Least one 
(11.8\%) of treatment option was hormonal pills (Ranasinghe et al, in 2013).

Informing young females about this serious disease is both a challenge and important investment in the health of the future generations of women (Mehmoosh, 2014). In this study more than three quarter of the students had heard about BSE. A study done in Sudan in 2013 showed that most of the participants were heard about BSE but only two third of the students reported performing BSE (Saadeldin et al, 2013). A study done in Ethiopia in 2014 showed that only just below $40 \%$ of the students had performed BSE (Segni et al, 2014). Ranasinghe et al, in 2013, claimed that nearly one fifth of the students were aware of how to perform BSE. Among them, less than $10 \%$ of the students had ever performed it. Suleiman, in 2012, reported that one third of the participants were aware of BSE, but only $11 \%$ had performed it (Suleiman, 2014).

The present study found that nearly one fifth of the students had performed BSE because of health officers' advice. Approximately $10 \%$ of them had performed because one of their family members had breast cancer. Least number of students performed for special medical check-up and presence of lump in the breast. Nde et al, study showed that the reasons for performing BSE were ordered by health personnel (15.1\%), fear for performing it (12.7\%) and media influence $(11.4 \%)$ were respectively. The least percentages of students had performed because one of their family members had breast cancer.

In our study nearly two third of students had not performed BSE in their life. Nearly one quarter of the participants mentioned lack of knowledge about technique of BSE and lack of interest were the barriers for performing the BSE. A study by Baamer Abobakar Ahmed in Yemen claimed that nearly one fifth of the students performed BSE and the barriers for performing the BSE as followed lack of knowledge about technique of BSE (55.9\%), unwanted (24.1\%), fear for performing it(28.1\%) and lack of time to do it (11.9\%) were respectively (Ahmed, 2010).
Although this study has revealed that students had good knowledge regarding breast cancer, the less number of the students had performed BSE in their life.

\section{CONCLUSION AND FUTURE WORK}

This study reveals the knowledge of breast cancer and practice of breast self-examination among female students in Faculty of Health Care Sciences, Eastern University, Sri Lanka. Most of the participants had heard about breast cancer. The overall knowledge regarding breast cancer was good including good knowledge in warning signs and treatment options but average knowledge in risk factors except family history. Majority of the students had heard about breast self-examination. However, less than half of the students had practiced breast self-examination in their life. We recommended to the educational institution to include an educational program which consists of risk factors, early detection and treatment methods of breast cancer. Health educational programme has to be done in the student community during their orientation period. Furthermore, we would like to recommend the University for further work that has to be done regarding increasing the level of awareness about BSE through possible and feasible methods.

\section{ACKNOWLEDGEMENT}

We wish to express our sincere thanks to the students who were participated in this study, Vice-chancellor, Easter University, Sri Lanka and Dean, Faculty of Health-Care Sciences, Easter University, Sri Lanka for their permission and valuable support to complete this research in a successful manner.

\section{REFERENCES}

WORLD HEALTH ORGANIZATION. Breast cancer: Early diagnosis and screening. 2017. 
Available

at:

http://www.who.int/cancer/prevention/diagnosi s-screening/breast-cancer/en/

WORLD HEALTH ORGANIZATION. Breast cancer: prevention and control 2014. Available at:

http://www.who.int/cancer/detection/breastcanc er/en/

MINISTRY OF HEALTH. Every four days one Sri Lankan woman dies of breast or cervical cancer - Colombo Page News Desk [Internet]. Aug 18. 2012. Available at: www.colombopage.com/archive_ 12A/Aug18_1345304191CH.

WORLD HEALTH ORGANIZATION. Cancer country profile. 2014. Available at: http://www.who.int/cancer/country-profiles/en/

MINISTRY OF HEALTH. Nutrition and Indigenous medicine (2017). Annual health bulletin, Sri Lanka-2015. Available at: http://www.health.gov.lk/moh_final/english/pu blic/elfinder/files/publications/AHB/2017/AHB \%202015.pdf

TABA'R L, DUFFY SW, VITAK B, CHEN HH \& PREVOST TC. The natural history of breast carcinoma: what have we learned from screening? Cancer. 199; 86: 449-62. Available at:

https://www.ncbi.nlm.nih.gov/pubmed/104302 53

NAOMAL MAP. Breast Cancer In Sri Lanka Is Rising, It Is Your Move. Sunday Leader. 2015. [Internet]. July 8. Available at: www.thesundayleader.lk/breast-cancer-in-srilanka.

SHERMA CD \& HOSSFELD DK. (5ed.). Breast cancer in manual of oncology. Bosch FX International Union against cancer. Middle East. Berlin Heidelberg/USA: Springer Verlag. 1990; 257-76.

VERMA S, MILES M, LUCA G, IAN E, MANFRED W \& JOSÉ J. Trastuzumab
Emtansine for HER2-Positive Advanced Breast Cancer for the EMILIA Study Group. N Engl J Med. 2013; 367:1783-1791. Available at: http://www.nejm.org/doi/pdf/10.1056/NEJMoa 1209124

HARIS JS, LIPPMAN ME, VERONESI U \& WILLETT W. Breast Cancer. New England Journal of Medicine. 1992; 327: 319 -328. Available at: http://www.nejm.org/medicalresearch/breast-cancer?subtopic=breast-

cancer\&sort $=$ score \&page $=8$

RANASINGHE HM, RANASINGHE N, RODRIGO C, SENEVIRATNE RDA \& RAJAPAKSE S. Awareness of breast cancer among adolescent girls in Colombo, Sri Lanka: a school based study. BMC Public Health. 2013; 13:1209.

Available at:http://bmcpublichealth.biomedcentral.com/ar ticles/10.1186/1471-2458-13-1209

FERLAY J, SOERJOMATARAM I, ERVIK M, DIKSHIT R, ESER S, MATHERS C et al. Cancer Incidence and Mortality Worldwide Lyon, France. 2013.

INTERNATIONAL AGENCY FOR RESEARCH ON CANCER; GLOBOCAN 2012. Available from: http://globocan.iarc.fr.

SENEVIRATNE S. Dr. R.L Spittle Oration: A breast cancer registry to improve quality and reduce disparities in breast cancer care - lessons learnt. The Sri Lanka Journal of Surgery. 2016; 34 (4): 16-20. Available at: http://sljs.sljol.info/articles/abstract/10.4038/slj s.v34i4.8316/

IARC WHO. Latest world cancer statistics. 2013. Available at: https://www.iarc.fr/en/mediacentre/pr/2013/pdfs/pr223_E.pdf

MOUSTAFA DG, ABD-ALLAH ES \& TAHA NM. Effect of a Breast-Self Examination (BSE) Educational Intervention among Female University Students. American Journal of Nursing Science. 2015; 4(4): 159-165. 
Available

at:

http://www.sciencepublishinggroup.com/j/ajns

OSIME OC, OKOJIE O, AIGBEKAEN ET \& AIGBEKAEN IJ. Knowledge attitude and practice about breast cancer among civil servants in Benin City, Nigeria. Annals of African Medicine. 2008; 7: 192-197. Available at:

https://www.ncbi.nlm.nih.gov/pubmed/196239 22

SEGNI MT, TADESSE DM, AMDEMICHAEL R \& DEMISSIE HF. (2014). Breast Selfexamination: Knowledge, Attitude, and Practice among Female Health Science Students at Adama Science and Technology University, Ethiopia. Gynecol Obstet (Sunnyvale). 2016; $6: 4$

KHOKHER S, QURESHI W, MAHMOOD S, SALEEM A \& Mahmud S. Knowledge, attitude and preventive practices of women for breast cancer in the educational institutions of Lahore, Pakistan. Asian Pac J Cancer Prev. 2011; 12(9):2419-24. Available at: https://www.ncbi.nlm.nih.gov/pubmed/222963 94

NEMENQANI D, ABDELMAQSOUD S, ALMALKI A, ORAIJA A \& AL-OTAIBI E. Knowledge, attitude and practice of breast selfexamination and breast cancer among female medical students in Taif, Saudi Arabia. Open Journal of Preventive Medicine. 2014; 4: 69-77. Available at: https://www.scirp.org/journal/PaperInformation .aspx?PaperID=42833

AL-JUNAIBI RM \& ALAM KHAN S. Knowledge and Awareness of breast cancer among university female students in Muscat, Sultanate of Oman- A pilot study. Journal of Applied Pharmaceutical Science. 2011; 01(10): 146-149. Available at: http://japsonline.com/admin/php/uploads/316_p df.pdf
SULEIMAN AK. Awareness and attitudes regarding breast cancer and breast self-examination among female Jordanian students. Journal of Basic and Clinical Pharmacy. 2014; 5(3): 74-78. Available at: www.jbclinpharm.org

LTIF R. Knowledge and attitude of Saudi female students towards breast cancer: A crosssectional study. Journal of Taibah University Medical Sciences. 2014; 9(4): 328-334. Available at: http://dx.doi.org/10.1016/j.jtumed.2014.05.004

MEHRNOOSH AZ, MUHAMAD HJ, ROSLIZA AM, IRMI ZI, SALMIAH S. Knowledge on breast cancer and practice of breast self -examination among selected female university students in Malaysia. MHSJ. 2011; 7:49-56.

SAADELDIN AI, AAMIR A, HAMZA MOHAMED M, HAFIZ MOHAMMED ELTAYEB A ALI \& GAMAL EHA EL SHALLALY. Knowledge, Attitude and Practice of Breast Self- Examination among Final Years Female Medical Students in Sudan. International Journal of Public Health Research. 2013; 1(1): 6-10. Available at: https:/www.researchgate.net/publication/26117 7341

NDE FP, ASSOB JCN, KWENTI TE, NJUNDA AL \& TAINENBE TRG. Knowledge, attitude and practice of breast self-examination among female undergraduate students in the University of Buea. BMC Research Notes. 2015; 8:43. Available at: https://www.ncbi.nlm.nih.gov/pubmed/258896 44

AHMED BA. Awareness and practice of breast cancer and breast-self-examination among university students in Yemen. Asian Pac J Cancerv Prev. 2010; 11(1):101-5. Available at: https://www.ncbi.nlm.nih.gov/pubmed/205939 37 